\title{
Susumu Ohno left us January 13, 2000, at the age of 71
}

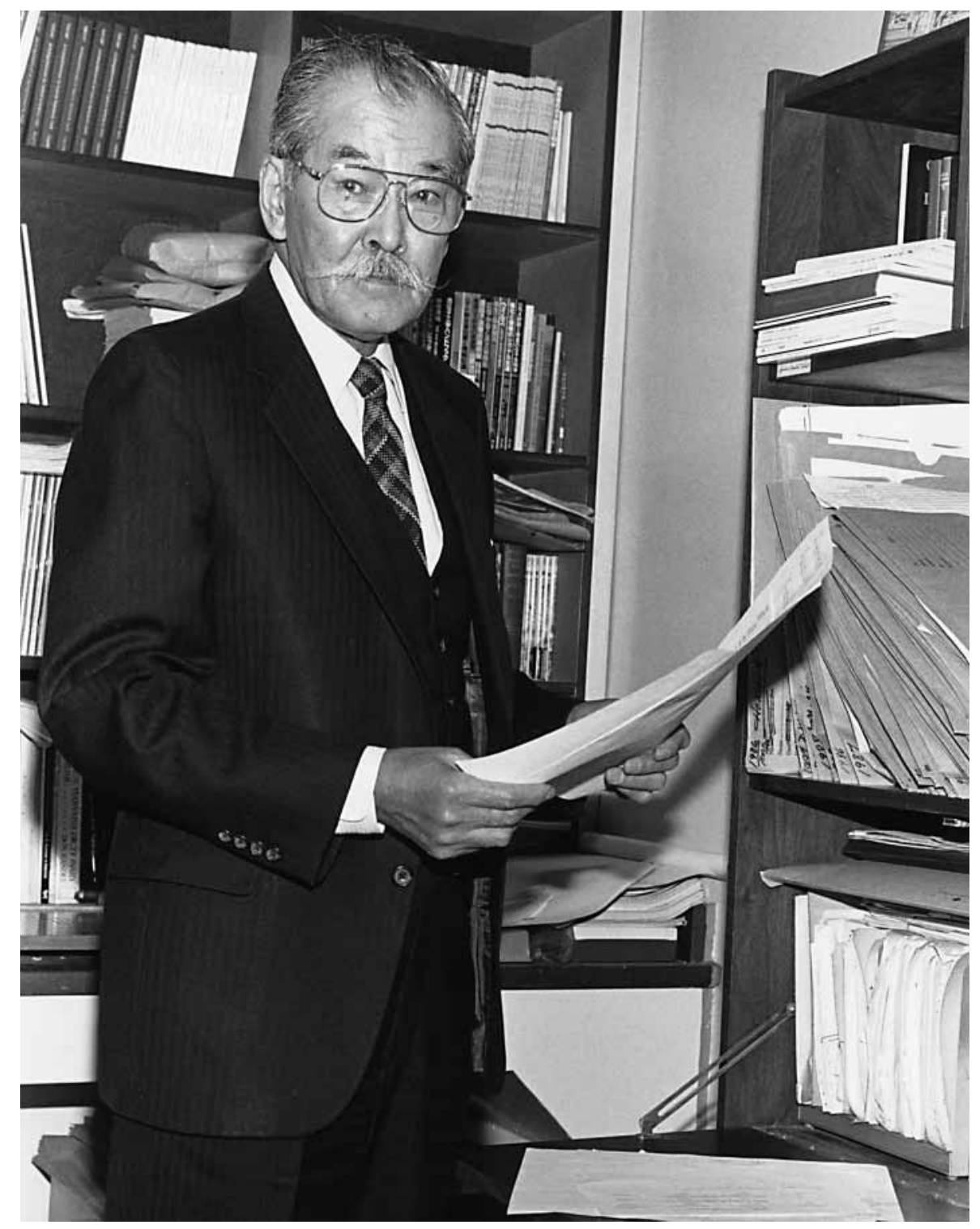

His passion for science derived from his life-long love of horses. He earned a Ph.D. in veterinary science at Tokyo University of Agriculture and Technology in 1949, and later a Ph.D. and D.Sc. from Hokkaido University. He came to the United States in 1951, as a visiting scholar to UCLA, and in 1952 joined the new research department at City of Hope Medical Center, where he remained in active research until 1996.

Dr. Ohno's discoveries in experimental cytogenetics were the prelude to his more global thinking on evolution. His research on the cytogenetics of sex chromosomes prepared the way for the Lyon hypothesis. 
His findings on the high degree of conservation of the X-chromosome throughout mammalia led to the proposal (known as Ohno's Law) that the female sex chromosome of all mammals was derived from a common ancestor. His classic 1971 book Evolution by Gene Duplication, which coined the term "junk DNA," pointed to one of the fundamental mechanisms of molecular evolution. His article "Genetic implication of karyological instability of malignant somatic cells" (Physiological Reviews 51:496-526, 1971) is a landmark in our understanding of cancer as a genetic disease and put forward the two-hit hypothesis of mutation-induced tumors.

Dr. Ohno's interest in using the human mind to deconvolute Fourier interference patterns (presented as music) into variations on the same theme led to his rules for setting DNA sequences to music as a means of divining the underlying repetitive element present in sequences of common origin. This extraordinary finding that common themes pointing to iterated ancestral short repetitive elements can be identified in many genes led to the identification of biological elements that are among our most ancient living fossils.

Among his many honors, Dr. Ohno was elected to the National Academy of Sciences in 1981, and in 1998 was awarded the inaugural Royal Danish Association Research Prize for his work on how new genes evolve.

To his fellow faculty members, Susumu was like a Buddhist priest, a teacher of the philosophy of science. He would train us in various ways. Training occurred when walking into Susumu's office as he was writing or concentrating. He was completely unaware of you or the world, so intent was his concentration that you usually just left without forcing a break. We all knew that we were not that good at concentrating but it was a state of mind to strive for. At weekly wine-tasting he made us let our inhibitions down and talked naked, politically uninhibited truth for a refreshing hour each week. Here, he ensured that our discussion always touched upon some charismatic figure who had shaped the world in some special way, as an example of what we individually could possibly do. Impressive was the fact that this history was usually of western civilization. The perpetrators of the historical events were not related to Susumu. They had shaped his thought; if they were kings, he had often memorized their lineage.

He played the devil's advocate role, criticizing our ideas, but fostering discussion by respecting those who argued with him. You just knew that he also did this to himself; it taught us how to step back and be critical of our ideas and of our thought experiments. If our idea or manuscript was good, then he would tell us this but sometimes only several months later. This was quite an honor and showed that he remembered, pondered, and gave his opinion after much thought.

But there were limits to logic. For example, he loved the Greeks "golden ratio" and consistently pointed out that this proportion could bring a natural beauty to visual experience. He showed how a profile of a thoroughbred horse fit this golden ratio. One day we xeroxed a photo of his beloved miniature horse and drew measurements on it to prove at wine tasting that the little horse did not fit the Greek ideal and therefore must be considered unappealing. He brushed our diagram away with the same tone and type of illogical justification he used for alcohol or smoking showing that it is intellectually OK to be illogical concerning some opinions so long as you are openly honest with yourself and others about how illogical you are being.

Gerald P. Holmquist

City of Hope Medical Center 